\title{
3-D surface properties of glacier penitentes over an ablation season, measured using a Microsoft Xbox Kinect
}

\author{
Lindsey I. Nicholson ${ }^{1}$, Michał Pętlicki ${ }^{2,3}$, Ben Partan ${ }^{4}$, and Shelley MacDonell ${ }^{3}$ \\ ${ }^{1}$ Institute of Atmospheric and Cryospheric Sciences, University of Innsbruck, Innsbruck, Austria \\ ${ }^{2}$ Institute of Geophysics, Polish Academy of Sciences, ul. Księcia Janusza 64, 01-452 Warsaw, Poland \\ ${ }^{3}$ Centro de Estudios Avanzados en Zonas Áridas (CEAZA), La Serena, Chile \\ ${ }^{4}$ University of Maine, Orono, USA \\ Correspondence to: Lindsey I. Nicholson (lindsey.nicholson@uibk.ac.at)
}

Received: 15 November 2015 - Published in The Cryosphere Discuss.: 19 January 2016

Revised: 7 August 2016 - Accepted: 9 August 2016 - Published: 2 September 2016

\begin{abstract}
In this study, the first small-scale digital surface models (DSMs) of natural penitentes on a glacier surface were produced using a Microsoft Xbox Kinect sensor on Tapado Glacier, Chile $\left(30^{\circ} 08^{\prime} \mathrm{S}, 69^{\circ} 55^{\prime} \mathrm{W}\right)$. The surfaces produced by the complete processing chain were within the error of standard terrestrial laser scanning techniques, but insufficient overlap between scanned sections that were mosaicked to cover the sampled areas can result in threedimensional (3-D) positional errors of up to $0.3 \mathrm{~m}$. Between November 2013 and January 2014 penitentes become fewer, wider and deeper, and the distribution of surface slope angles becomes more skewed to steep faces. Although these morphological changes cannot be captured by manual point measurements, mean surface lowering of the scanned areas was comparable to that derived from manual measurements of penitente surface height at a minimum density of $5 \mathrm{~m}^{-1}$ over a $5 \mathrm{~m}$ transverse profile. Roughness was computed on the 3-D surfaces by applying two previously published geometrical formulae: one for a 3-D surface and one for single profiles sampled from the surface. Morphometric analysis shows that skimming flow is persistent over penitentes, providing conditions conducive for the development of a distinct microclimate within the penitente troughs. For each method a range of ways of defining the representative roughness element height was used, and the calculations were done both with and without application of a zero displacement height offset to account for the likelihood of skimming air flow over the closely spaced penitentes. The computed roughness values are on the order of $0.01-0.10 \mathrm{~m}$ during the early part of the ablation season, increasing to $0.10-0.50 \mathrm{~m}$ after the
\end{abstract}

end of December, in line with the roughest values previously published for glacier ice. Both the 3-D surface and profile methods of computing roughness are strongly dependent on wind direction. However, the two methods contradict each other in that the maximum roughness computed for the 3-D surface coincides with airflow across the penitente lineation, while maximum roughness computed for sampled profiles coincides with airflow along the penitente lineation. These findings highlight the importance of determining directional roughness and wind direction for strongly aligned surface features and also suggest more work is required to determine appropriate geometrical roughness formulae for linearized features.

\section{Introduction}

Penitentes are spikes of snow or ice, ranging from a few centimetres up to several metres in height that can form during the ablation season on snowfields and glaciers. They are a common feature of high-elevation, low-latitude glaciers and snowfields (e.g. Hastenrath and Koci, 1981; Corripio and Purves, 2005; Winkler et al., 2009) where very low humidity, persistently cold temperatures and sustained high solar radiation favour their development (Lliboutry, 1954). As cryospheric water resources are relatively important to local dry season water supply in arid mountain ranges (Kaser et al., 2010), there is potential value in understanding how penitentes might influence both runoff and atmospheric humidity. 
Penitentes form linearized, inclined fins of snow or ice on the surface. Both the latitudinal range (within $55^{\circ}$ of the Equator on horizontal surfaces) and geometry (aligned with the arc of the sun across the sky and tilted toward the sun at local noon) of penitentes are governed by solar-to-surface geometry (Lliboutry, 1954; Hastenrath and Koci, 1981; Bergeron et al., 2006; Cathles et al., 2014). During the initial stages of penitente development, ablation is thought to proceed by sublimation alone driven by the low atmospheric humidity. Surface irregularities focus reflected solar radiation within depressions (Amstutz, 1958; Corripio and Purves, 2005; Lhermitte et al., 2014; Claudin et al., 2015) such that the energy receipts, and consequently ablation, are enhanced in the hollow and the surface irregularity becomes amplified. Subsequently, as the surface relief increases, a more humid microclimate is thought to develop in the hollows between penitentes, suppressing sublimation and allowing melting in the depressions. Meanwhile, the penitentes tips continue to ablate by sublimation alone (Lliboutry, 1954; Drewry, 1970; Claudin et al., 2015) and, as melting requires approximately an eighth of the energy of sublimation to remove the same amount of ice, the spatial differentiation of ablation process between penitente trough and tip is very effective at amplifying the penitente surface relief.

The altered partitioning of ablation between sublimation and melting that occurs in penitente fields, as compared to surfaces without penitentes (e.g. Lliboutry, 1998; Winkler et al., 2009; Sinclair and MacDonell, 2015), is expected to alter the rate of mass loss and meltwater production of snow and ice fields during the ablation season, but this has not yet been fully quantified. Previous studies, based on modelling idealized penitente surfaces, have investigated the impact of penitentes on the shortwave radiative balance, and they suggest that penitentes reduce effective albedo by up to $40 \%$ compared to flat surfaces (Warren et al., 1998; Corripio and Purves, 2005; MacDonell et al., 2013; Cathles et al., 2014; Lhermitte et al., 2014). In addition to altering the radiative properties of the surface, the development of penitentes also manifestly alters the surface roughness properties, but neither the impact of penitentes on surface roughness nor the associated impact on turbulent energy fluxes has been investigated. The roughness of snow and ice surfaces is particularly prone to varying in space and time (e.g. Smeets et al., 1999; Brock et al., 2006; Fassnacht et al., 2009b). Wind profile measurements over linearized sastrugi surface features shows that the derived aerodynamic roughness length varied from 1 to $70 \mathrm{~mm}$ over a $120^{\circ}$ range of impinging wind direction (Jackson and Carroll, 1978). While penitentes are a relatively rare form of linearized surface feature, linear crevasses are widespread, and penitentes offer a unique test bed for investigating the significance of linearized features on effective surface roughness for various wind directions.

Measurements of natural penitentes required to examine their morphometry and roughness are rare (e.g. Naruse and Leiva, 1997) and difficult to obtain because the complex, and partially overhanging, surface prevents the use of simplified automated tools such as photogrammetric determination of surface profile heights (e.g. Fassnacht et al., 2009a; Manninen et al., 2012) or line-of-sight surveying from fixed positions. Recent advances in close-range photogrammetry and mobile depth-of-field sensors and efficient feature tacking software used in interactive computer gaming offer potentially useful tools that can be applied to resolve such problems in earth science (e.g. Mankoff and Russo, 2013; Smith et al., 2016). In this study a Microsoft Xbox Kinect sensor is used as a close-range mobile distance ranger to produce a series of small-scale digital surface models (DSMs). The method of DSM generation is evaluated against standard terrestrial laser scanning, and the Kinect-derived DSMs of the penitentes are used to (i) perform the first detailed examination of the morphometry of natural penitentes over the course of an ablation season, (ii) compare the volume change computed from DSM differencing with estimates based on manual measurements of surface lowering and (iii) examine the geometrical roughness properties of the sampled penitente surfaces.

\section{Methods}

\subsection{Description of field site}

Tapado Glacier $\left(30^{\circ} 08^{\prime} \mathrm{S}, 69^{\circ} 55^{\prime} \mathrm{W}\right)$ lies in the upper Elqui Valley of the semiarid Andes of the Coquimbo Region of Chile (Fig. 1). The glacier is relatively accessible and is known to develop penitentes every summer (Sinclair and MacDonell, 2015). Two separate study areas were analysed. Firstly, a test site was established at a patch of snow penitentes within a dry stream bed at $4243 \mathrm{~m}$ a.s.l. in the glacier foreland (Fig. 1). This site was used to (i) test instrumental set-ups in order to optimize the field operation of the Kinect sensor and (ii) compare the performance of the Kinect sensor against a terrestrial laser scanner (TLS). This location was chosen due to the logistical difficulties of transporting the TLS to the glacier. Subsequently, two study plots were established at an elevation of $4774 \mathrm{~m}$ a.s.l. on the glacier ablation zone (Fig. 1). These sites were scanned repeatedly with the Xbox Kinect (see Sect. 2.3) during the core ablation season between the end of November 2013 and the beginning of January 2014. The location and layout of the two glacier sites is shown in Fig. 1a. Site A ( $5 \mathrm{~m}$ by $2 \mathrm{~m})$ was measured four times: on 25 November, 11 December, 20 December and 3 January. Site B ( $2 \mathrm{~m}$ by $2 \mathrm{~m}$ ) was only measured on the last three dates. The corners of the study sites were marked with $2 \mathrm{~m}$ lengths of plastic plumbing piping hammered vertically into the snow or drilled into the ice (Fig. 1c). In order to locate the study sites in space and to provide a common reference for each survey date, marker stake positions were measured using a Trimble 5700 differential GPS with Zephyr antenna on the 25 November, with a base station in 


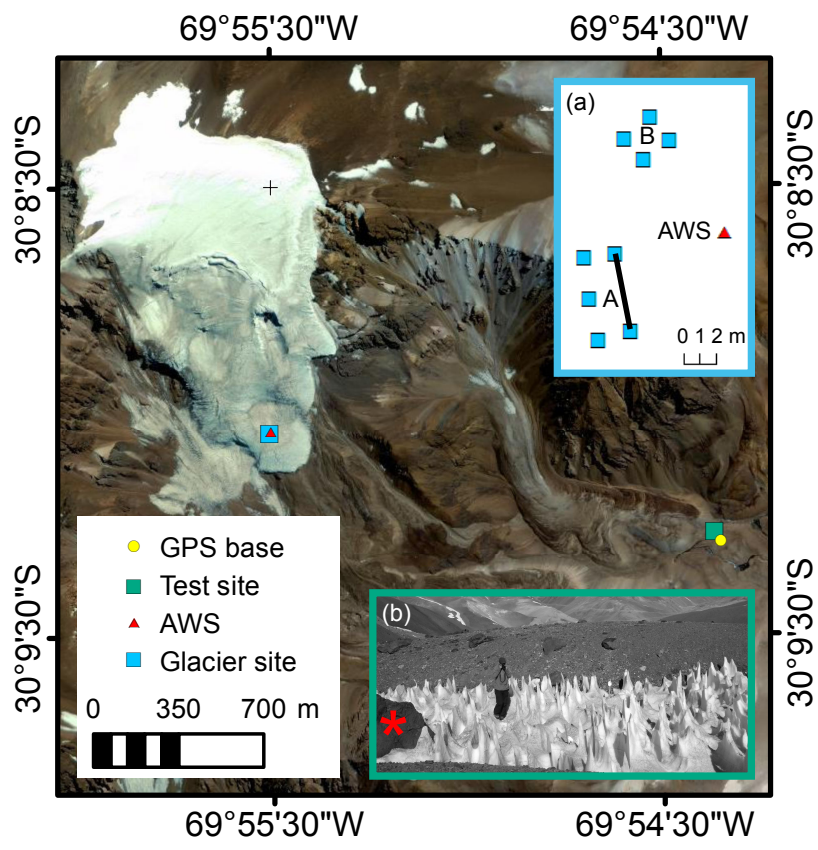

Figure 1. Map of Tapado Glacier in the Elqui catchment of the Coquimbo Region of Chile, showing the location of the measured sites and insets of (a) the glacier site layout, showing the location of the horizontal reference (black line), and (b) the test site, indicating the boulder (red star) at which the Kinect scans were compared against TLS.

the glacier foreland. On each visit to the glacier, when possible, the stakes were hammered further into the snow and the resultant lowering of the stake top was noted. The maximum standard deviations of the GPS stake positions were $<1.0,1.1$ and $1.7 \mathrm{~cm}$ in easting, northing and elevation, respectively, with combined $X Y Z$ standard deviation $<2.0 \mathrm{~cm}$ for all stakes (Table S1 in the Supplement). Error on the manual measurements of height offsets of the marker stakes on subsequent survey dates is conservatively estimated to be $2.0 \mathrm{~cm}$. This results in total positional errors of the ground control points (GCPs) at each scan date of between 2.3 and $2.7 \mathrm{~cm}$ depending on the stake. Manual measurements of surface lowering were made along the eastern long side of site A. All surfaces heights were referenced to the elevation of the glacier surface at the up-glacier end of this cross profile at the date of installation. An automatic weather station (AWS) on a free-standing tripod was installed beside the two glacier plots to provide meteorological context for the measurements (Fig. 1).

\subsection{Terrestrial laser scanning}

At the test site surface scans produced by the relatively new Kinect sensor were compared with those produced by the well-established TLS method. The TLS system used was an Optech ILRIS-LR scanner, which is a long-range terrestrial laser scanner especially suitable for surveying snow and ice surfaces as it has a shorter wavelength laser beam $(1064 \mathrm{~nm})$ than other models. This equipment surveys surface topography based on time-of-flight measurement of a pulsed laser beam reflected to a given angle by a system of two rotating mirrors. It has a raw range accuracy of $4 \mathrm{~mm}$ at $100 \mathrm{~m}$ distance, raw angular accuracy of $80 \mu \mathrm{rad}$, beam diameter of $27 \mathrm{~mm}$ at $100 \mathrm{~m}$ distance and beam divergence of $250 \mu \mathrm{rad}$. The instrument was placed in five locations around the surveyed snow patch and boulder, overlooking it from different directions. Positions of the TLS were measured with Trimble 5700 differential GPS with Zephyr antennae in static mode. Seventeen point clouds were obtained with nominal resolution of $0.11-0.75 \mathrm{~cm}$. Resulting point clouds were corrected for atmospheric conditions (pressure, temperature and humidity) and trimmed with ILRIS Parser software, aligned with Polyworks IMAlign software into a common local coordinate system and georeferenced with differential GPS measurements using Polyworks IMInspect software. The alignment error of the point clouds as estimated by this software is $0.36-0.87 \mathrm{~cm}$ and comparison with GCPs gives an error of $5.65 \mathrm{~cm}$. The TLS scan of the snow penitentes is presented as an example of the nature of the DSM that can be obtained within a penitente field using TLS (Fig. 2). Unfortunately, the scans of snow penitentes could not be carried out with both the TLS and Kinect on the same day, so direct comparison of the TLS and Kinect scans is instead performed on a reference boulder within the test site, whose surface is assumed unchanged between different scan dates.

\subsection{Kinect surface scanning}

The Kinect sensor emits a repeated pattern of structured infrared (IR) beams and records the pattern distortion with an IR camera. The depth-of-field calculation is performed via a proprietary algorithm and a distance map is the raw data output. Using the standard calibration the static raw depth field resolution of the Kinect is $1 \mathrm{~mm}$ and the distance error is $<1.0 \mathrm{~cm}$ at the distance range of the penitente scans (Mankoff and Russo, 2013).

For its original gaming usage, the Kinect is in a fixed position and proprietary software uses feature tracking to track the movements of players moving within the field of view of the Kinect. However, the inverse of this workflow can also be applied whereby the Kinect sensor is moved interactively around a static surface or three-dimensional (3-D) body, using the same feature tracking to compute the position of the sensor relative to the object and thereby allowing a point cloud reconstruction of the object. In this work we apply the second work flow and sample Kinect data using the ReconstructMe ${ }^{\mathrm{TM}} 2.0$ software package. In common with alternative reconstruction packages that are compatible with the Kinect, ReconstructMe ${ }^{\mathrm{TM}}$ performs bilateral filtering on the output depth map frame and converts the pixel version of each depth map frame to 3-D coordinate maps of vertices 


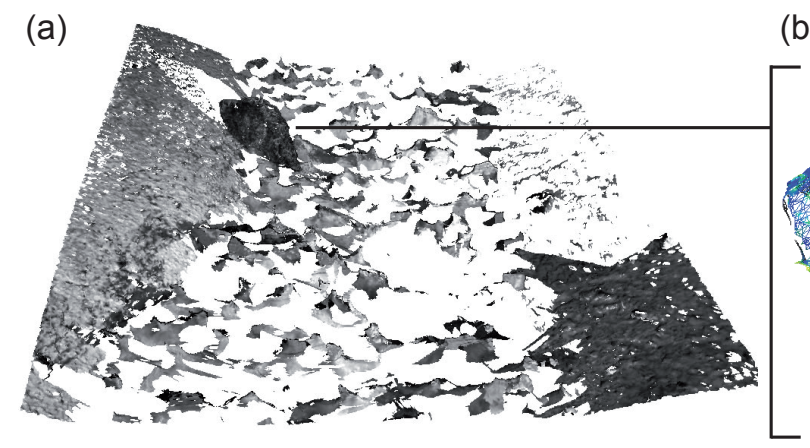

(b)
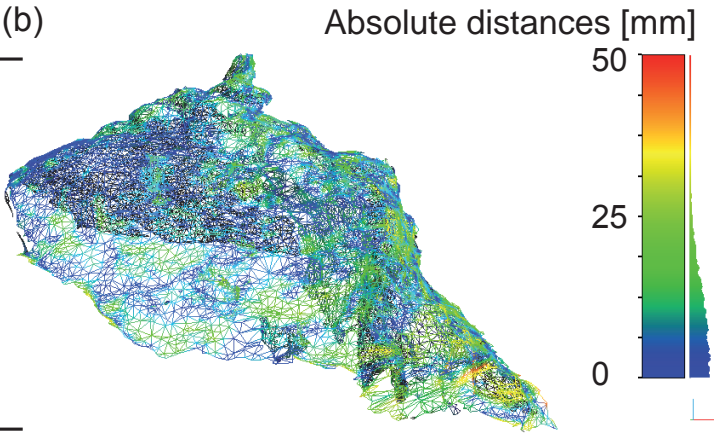

Figure 2. (a) Oblique view of the TLS-derived DSM of the test site highlights the patchy coverage of the penitentes obtained by this method. (b) Absolute differences between DSMs of the sample boulder produced using TLS and Kinect.

and normals. An iterative closest point (ICP) alignment algorithm is then applied frame by frame at three scales to repeatedly rotate and translate the depth field to determine camera position and an aligned surface, giving weighted preference to portions of the surface that are perpendicular to the line of sight. The ReconstructMe ${ }^{\mathrm{TM}}$ software has the advantage of producing surface meshes in real time, so that the operator can check the scan quality and coverage at the time of capture; however, the disadvantage is that the raw point cloud is not saved and if the real-time tracking is lost a new scan must be started.

The Xbox Kinect was connected via a $5 \mathrm{~m}$ powered USB extension cord to an MSI GE60 gaming laptop, powered using a $240 \mathrm{~V} 600 \mathrm{~W}$ inverter connected to the $160 \mathrm{Ah} 12 \mathrm{~V}$ battery of the automatic weather station on the glacier. Scans were carried out by two people: one moving the Kinect across the penitente field and the other monitoring the quality of the surface being generated on screen. In bright conditions, the return IR signal of the Kinect is swamped by natural radiation over snow and ice surfaces, which reflect a high proportion of incident shortwave radiation and absorb or scatter much of the longwave radiation signal. Therefore, scanning was carried out at twilight or just after nightfall. Sudden movements caused by the operator slipping or the snow compacting underfoot resulted in the ReconstructMe software losing its tracking of common reference points. Consequently, each study site was scanned in small sections and 3 to 13 overlapping surface meshes were used to cover the area of each study site. Recommendations for using the Kinect in this way are given in the Supplement (Sect. S1).

\subsection{Kinect surface mesh processing}

The full mesh processing procedure using the freely available Meshlab software is presented in the Supplement (Sect. S2) and briefly described here. Small surface components, unreferenced and duplicated vertices, were removed from the meshes using built-in filters. The component meshes that cover each sampling date at a single site were aligned using an ICP algorithm which distributes the alignment er- ror evenly across the resultant mosaicked surface mesh. Alignment solutions consistently had mean distributed error $<4 \mathrm{~mm}$ (Table S1). The aligned meshes were flattened into a single layer, remeshed using a Poisson filter and resampled to reduce the point density by setting a minimum vertex spacing of $2.5 \mathrm{~mm}$.

The surface mesh for each scan date was georeferenced in Polyworks software using the known coordinates of the base of the marker stakes at the time of each scan because the upper portions of the symmetrical stakes are often poorly captured by the meshing software. The local elevation zero was set to be the north-eastern corner of site A. The mismatch evident in the georeferencing step (Table 1) is much larger than the mesh alignment error (Table S2). This is most likely an artifact of a combination of (i) reduced mesh quality at the margins of the component scans and (ii) insufficient overlap between some scan sections producing distortion within the mesh alignment.

To eliminate the marker stakes and any data gaps near the margins of the study areas, each surface mesh was subsampled within the staked area. The subsampled area for site A is a 2.0 by $3.5 \mathrm{~m}$ horizontal area $\left(7.00 \mathrm{~m}^{2}\right)$ and site $\mathrm{B}$ is a $1.5 \times 1.5 \mathrm{~m}$ horizontal area $\left(2.25 \mathrm{~m}^{2}\right)$, shown in the examples in Fig. 3. Mesh vertices and an index file of the vertices comprising each face were exported from Meshlab for subsequent analysis in Matlab software.

\subsection{Calculations of surface geometrical properties}

The geo2d and geo3d toolboxes (available from the Matlab File Exchange) were used to compute the face areas and normals of the mesh, from which surface height distribution, aspect and dip of the sampled surface were calculated, weighted by the ratio of each face area to the total surface area of all faces. As the surfaces contain overhanging parts, DSM differencing cannot be performed by simple subtraction. Instead, volumes for all surfaces were computed relative to a base-level horizontal reference. Volumes relative to this horizontal reference for upward-facing triangles were computed column-wise by projecting the area of 
Table 1. Maximum absolute georeferencing error at each marker stake for site A and B, relative to the standard deviation of the differential GPS measurement.

\begin{tabular}{lrrrrrr}
\hline & $\begin{array}{r}\Delta X \\
(\mathrm{~mm})\end{array}$ & $\begin{array}{r}\Delta Y \\
(\mathrm{~mm})\end{array}$ & $\begin{array}{r}\Delta Z \\
(\mathrm{~mm})\end{array}$ & $\begin{array}{r}\Delta X Y \\
(\mathrm{~mm})\end{array}$ & $\begin{array}{r}\Delta X Y Z \\
(\mathrm{~mm})\end{array}$ & $\begin{array}{r}\text { dGPS } X Y Z \text { standard } \\
\text { deviation }(\mathrm{mm})\end{array}$ \\
\hline A-1 & 63 & 25 & 38 & 68 & 77 & 17 \\
A-2 & 214 & 118 & 259 & 233 & 312 & 15 \\
A-3 & 14 & 57 & 53 & 57 & 62 & 14 \\
A-4 & 23 & 29 & 61 & 33 & 69 & 16 \\
A-5 & 54 & 32 & 128 & 56 & 139 & 16 \\
B-1 & 59 & 46 & 19 & 75 & 77 & 17 \\
B-2 & 121 & 11 & 102 & 164 & 193 & 12 \\
B-3 & 11 & 48 & 2 & 49 & 49 & 12 \\
B-4 & 85 & 37 & 34 & 85 & 92 & 16 \\
\hline
\end{tabular}

(a)

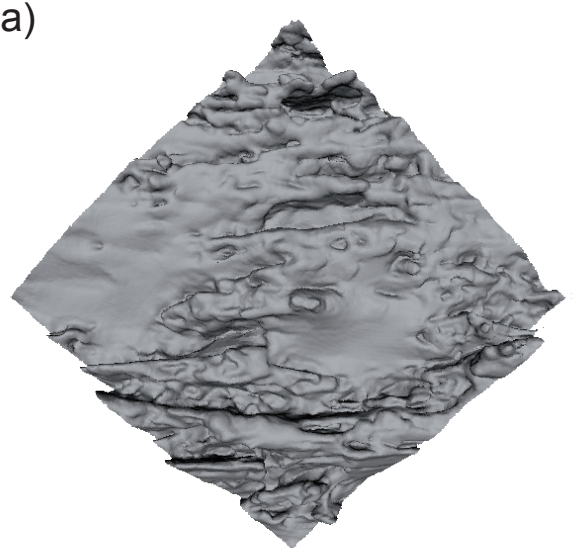

(b)

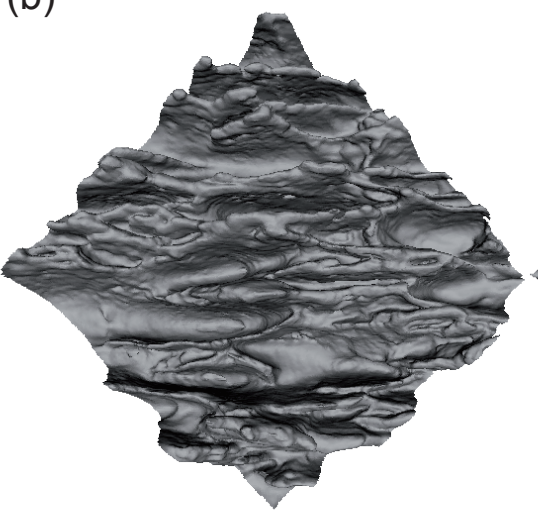

(c)

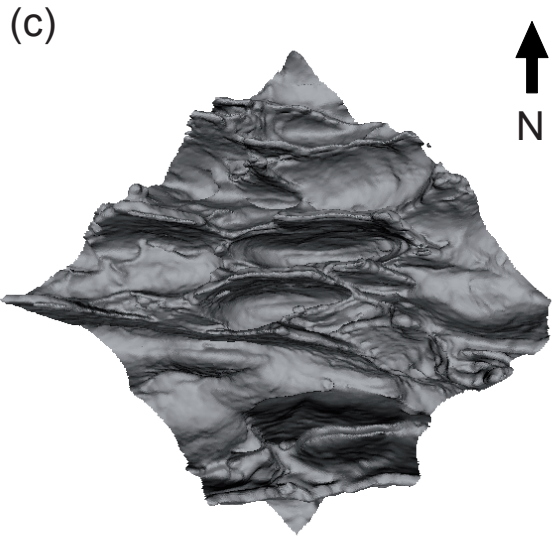

Figure 3. Shaded DSM meshes of N-S-orientated DSMs for the $1.5 \mathrm{~m} \times 1.5 \mathrm{~m}$ glacier site B on (a) 12 December 2013, (b) 20 December 2013 and (c) 3 January 2013 obtained using the Kinect.

each triangular face onto the reference surface and using the height coordinate of the triangle centroid as the height dimension for each column. These were summed and volumes for overhanging triangles, calculated in the same way, were subtracted to derive the total volume between the reference surface and each scanned penitente surface. Successive volumes were subtracted to obtain the volume change over each measurement interval.

\subsection{Manual measurements of surface change}

Traditional single-point stake measurements of glacier surface lowering are unreliable within the inhomogeneous surface of a penitente field. One alternative is to measure surface lowering at intervals along a profile perpendicular to the main axis of alignment of the penitentes. Such a reference was installed along the $5 \mathrm{~m}$ long eastern margin of site A, between two longer corner stakes drilled $3 \mathrm{~m}$ into the ice using a Kovacs hand drill. The distance between a levelled string and the glacier surface was measured using a standard tape measure at $0.2 \mathrm{~m}$ intervals on 23 November. Subsequent measurements, on 12 and 21 December and on 4 January, were made at $0.1 \mathrm{~m}$ intervals. All measurements were recorded to the nearest centimetre, and the error on each measurement is estimated to be $2.0 \mathrm{~cm}$, which is assumed to capture the error associated with the horizontal position of the measurements along the reference frame and the vertical measurements of the distance to the surface beneath.

\subsection{Calculations of geometric surface roughness}

The aerodynamic roughness length $\left(z_{0}\right)$ is the distance above the surface at which an extrapolation of a logarithmic wind speed profile under neutral conditions towards the surface would reach zero. Over taller roughness elements the level of momentum transfer between the airflow and the surface roughness elements is displaced upwards by a distance, termed the zero-plane displacement $\left(z_{\mathrm{d}}\right)$. Above particularly rough surfaces, a roughness sublayer is formed in the lowest part of the surface layer within which surface roughness elements create a complex 3-D flow that is almost chaotic. Where roughness elements are widely spaced, the separated flow over obstacles reattaches to the surface before the subsequent obstacle is reached. More closely packed roughness 
elements experience a wake interference regime, and in the most densely packed arrays of roughness elements skimming flow occurs (Grimmond and Oke, 1999). At the top of the roughness sublayer individual wakes caused by surface obstacles are smeared out and the flow is independent of horizontal position, and, thus, observations at this level represent the integrated surface rather than individual surface obstacles. This level is known as the blending height $\left(z_{r}\right)$. All these properties are dependent on the size and arrangement of surface roughness elements.

As it is logistically challenging to deploy instrumentation to determine roughness parameters from atmospheric profile or eddy covariance measurements on glacier surfaces, efforts have been made to instead use methods based on properties such as radar backscatter (e.g. Blumberg and Greeley, 1993) or more readily measurable surface terrain properties (e.g. Kondo and Yamazawa, 1986; Munro, 1989; Fassnacht et al., 2009a; Andreas, 2011; Smith et al., 2016). Grimmond and Oke (1999) tested several methods of determining apparent aerodynamic properties from surface morphometry in urban environments, which are among the roughest surface conditions encountered in the atmospheric boundary layer, and found that morphometric determinations of surface roughness do not clearly underperform in comparison with aerodynamic methods, suggesting that morphometric measurements of roughness are worth pursuing.

There are a number of formulations for deriving $z_{0}$ from geometrical measurements (see summary in Smith et al., 2016), the simplest of which is to take the standard deviation of the surface elevations as a measure of roughness (Thomsen et al., 2015). In this work, the surface meshes were analysed for roughness on the basis of a widely used relationship established by Lettau (1969), initially developed for isolated, regular obstacles distributed over a plane:

$z_{0}=0.5 h\left(\frac{s}{S}\right)$,

where $h$ is the height of the obstacles, $s$ is the upwind silhouette area of each obstacle and $S$ is the specific area occupied by each roughness element obstacle, also referred to as its lot area. Isolated roughness elements of regular geometry distributed over a horizontal plane are a poor analogy for the irregular surface topography of a penitente field, and the applicability of this formulation over penitentes has not been established. However, on the basis of wind profile measurements over a glacier surface, Smeets et al. (1999) suggest the formulation has merit. Here we apply the analysis as an illustration of the nature of the results generated from such an approach over penitentes and hope that future aerodynamic roughness lengths obtained from micrometeorological measurements can be compared to these morphometrically derived ones.

Roughness values computed using Eq. (1) over 3-D snow surfaces have been shown to vary widely depending on the methods of surface interpolation used (Fassnacht et al., 2014) due to the influence on interpolation method on the unit surface area occupied by each roughness element. However, the high-resolution meshes produced in this study can be expected to adequately capture the surface properties as no extrapolation or interpolation procedure is needed. Macdonald et al. (1998) state that for irregular obstacles $h$ can be replaced by average obstacle height, $s$ with the sum of all the upwind silhouette areas and $S$ with the total area covered by the obstacles. While the upwind silhouette area, and indeed surface area in any direction, is relatively easily defined for each surface mesh area using trigonometry, it is difficult to define individual roughness elements and their representative heights due to the lack of an apparent base level (Smith et al., 2016). Here we first detrend the surfaces to remove any general surface slope at the site, then compute the roughness for the detrended 3-D meshes, assuming that the roughness elements cover the whole surface area (i.e. $S$ is the horizontal area of the study site), and for four possible representations of average obstacle height $(h)$ as follows: (i) the maximum range of the detrended mesh; (ii) twice the standard deviation of the detrended surface mesh; (iii) mean mesh height above the mesh minimum; and (iv) median mesh height above the minimum.

These data are computed for illustrative purposes only as it is reported that Eq. (1) fails when the roughness element density exceeds 20-30\% (Macdonald et al., 1998), as is expected for penitente fields. High-density roughness elements mean that they interfere with the airflow around each other, and upwards displacement of the zero wind velocity level means that effective roughness is a result of the roughness elements above this zero velocity displacement plane, and the zero displacement height, gives an indication of the penetration depth of effective turbulent mixing into the penitente field. Accordingly, we additionally present sample calculations of 3-D roughness on the detrended surface meshes using three possible realizations of $z_{\mathrm{d}}$, as, like $h, z_{\mathrm{d}}$ is also unknown in the case of the penitente fields being sampled. In the first case, $z_{\mathrm{d}}$ is taken to be $h$, in the second $2 / 3 h$, which is a widely used standard in forests and other complex terrain applications (Brutsaert, 1975), and in the third 1/3 $h$. Each $z_{\mathrm{d}}$ case is computed for the four realizations of $h$ used as before. Equation (1) (for irregular obstacles) is then applied to the roughness elements remaining above the plane of the general surface slope offset by a distance $z_{\mathrm{d}}$ above the minimum height of the surface mesh. The representative height $h$ for this portion of the mesh exceeding the plane is taken to be the mean area-weighted height of all triangles above this plane, $s$ is the summed frontal area of all mesh triangles above $z_{\mathrm{d}}$ with respect to the chosen wind direction and $S$ is the total horizontal area of the study site.

Munro $(1989,1990)$ modified the formula of Lettau (1969) to be applied to a single irregular surface cross section of length $X$, sampled perpendicular to the wind direction. This modified formulation is easier to work with on a glacier where the roughness elements are irregular, closely spaced 
and generally poor approximations of objects distributed over a plane. Instead of having to define an obstacle height above the plane, $h$ is replaced with an effective height $h *$ expressed as twice the standard deviation from the standardized mean profile height; $s$ is replaced with $h * X / 2 f$, in which $f$ is the number of profile sections that are above the mean elevation; and $S$ is replaced with $(X / f)^{2}$. This approach approximates the surface elevation profile as rectangular elements of equal size and has been shown to give results within $12 \%$ of the silhouette area determined by integrating between true topographic minima (Munro, 1989). Importantly, roughness values derived this way over snow, slush and ice surfaces show reasonable agreement with roughness values derived from wind profiles (Brock et al., 2006). To investigate the nature of the roughness computed this way for north-south and east-west impinging wind directions, cross profiles longer than $1.5 \mathrm{~m}$ at $0.1 \mathrm{~m}$ intervals orientated $\mathrm{E}-\mathrm{W}$ and $\mathrm{N}-\mathrm{S}$ were extracted from each scanned surface. Cross sections were detrended to remove the influence of any general surface slope at the site, and roughness was computed on each of these cross-sectional profiles following the modifications of Munro. Mean profile roughness for these two wind directions are presented for each sampled surface.

\section{Results}

\subsection{Evaluation of the quality and suitability of penitente scans by TLS and Kinect}

The test site was well-developed snow penitentes $0.5-1.0 \mathrm{~m}$ in height in a channel (Fig. 1b). TLS scans of these penitentes were taken from five different vantage points above the penitentes. The penitente surface produced by the TLS had surface slope ranging between -30 and $90^{\circ}$, indicating that overhanging surfaces within the penitente field can be captured. However, the limitations of this conventional fixedpoint scanning system in capturing the penitente surfaces is illustrated by the fact that only $58 \%$ of the total surveyed horizontal area could be scanned, as the deepest parts of the troughs were obscured from the view by the surrounding penitentes (Fig. 2a). By comparison, the hand-held, mobile nature of the Kinect means that the whole surface of the penitente field can be captured as the field of view can be adjusted into almost limitless close-range positions, although the close-range Kinect sensor is impractical to apply over large areas.

For the direct comparison of the two methods on a reference boulder, the Kinect-derived surface, produced from three mosaicked meshes, was aligned to the surface produced from the TLS point clouds. The TLS scan was incomplete, with parts of the top and overhanging surfaces of the boulder missing due to being obscured from the TLS survey positions, while the Kinect scan achieved complete coverage of the boulder. The difference between the two aligned meshes where overlapping data existed was always $<2 \mathrm{~cm}$ (Fig. 2b), which is well within the error of the georeferenced TLS surface model. Larger differences in Fig. 2b, up to $5 \mathrm{~cm}$, occur only where there are holes in the surfaces being compared.

It is difficult to formally assess the total error of the surfaces produced by the Kinect scans because the workflow involves several black box processing steps. The mean alignment errors of the mesh mosaicking step in Meshlab is $<0.4 \mathrm{~cm}$ and quantifiable errors associated with the GPS positions, subsequent measurement of the stake bottom positions relative to the GPS positions are all $<2.0 \mathrm{~cm}$. However, the 3-D georeferencing error in this study is large (Table 1) compared to the other sources and is therefore taken as a reasonable value for the error of the total process chain. Errors given on the seasonal mass, volume and surface changes are based on summing the squares of the mean elevation difference between the marker stakes and GCPs at each site on the first and last survey dates.

\subsection{Meteorological conditions}

During the study period one significant snowfall event occurred on the 8 December 2013, when the sonic ranger recorded a surface height increase of $0.09 \mathrm{~m}$ over the course of the day (Table 2). Surface albedo and temperature are derived from radiation measurements that sample an area beneath the instrument. Surface temperature was calculated from measured surface longwave emissions, assuming emissivity of 1 . Over the study period, air temperature and atmospheric longwave receipts increase, while albedo decreases and derived surface temperature increases (Table 2). Thus, over the course of the study, atmospheric energy supply increases and surface properties become more conducive to melting. The warming atmosphere is clearly expressed in the positive degree days of the three periods which are 3.7, 2.2 and 31.5 over the 16-, 9- and 14-day-long periods respectively. Hourly surface temperatures exceed the melting point in 22,38 and $43 \%$ of cases in each period respectively. Daily surface lowering rates calculated between the hourly mean sensor-to-surface distance recorded by the AWS sonic ranger at midnight at the end of the survey days indicates lowering rates of 17,37 and $56 \mathrm{~mm} \mathrm{~d}^{-1}$ over the three measurement intervals, confirming that the increasing energy receipts translate into increasing rates of surface lowering at the AWS.

\subsection{Areal scans of penitente surfaces}

Surface lowering rates derived from the calculated volume changes per unit area are 21,41 and $70 \mathrm{~mm} \mathrm{~d}^{-1}$ over each interval at site $\mathrm{A}$, and 57 and $61 \mathrm{~mm} \mathrm{~d}^{-1}$ over the last two intervals at site B. Surface lowering calculated as the difference between successive hypsometric mean mesh elevation for each site were within a few millimetres of the volume computations: 22,38 and $69 \mathrm{~mm} \mathrm{~d}^{-1}$ for the three measured intervals at site $\mathrm{A}$, and 54 and $60 \mathrm{~mm} \mathrm{~d}^{-1}$ for the last 
Table 2. Mean meteorological conditions during the measurement intervals: incoming shortwave (SW in), albedo ( $\alpha$ ), incoming longwave (LW in), wind speed $(u)$, wind direction (dir), surface temperature computed from measured outgoing longwave radiation $(T$ surface), air temperature ( $T$ air), relative humidity $(\mathrm{RH})$, air pressure $(P)$ and the distance between the sonic ranger and the glacier surface (dist).

\begin{tabular}{|c|c|c|c|c|c|c|c|c|c|c|}
\hline & $\mathrm{SW}$ in & $\alpha$ & $\mathrm{LW}$ in & $u$ & dir & $T$ surface & $T$ air & RH & $P$ & dist \\
\hline & $\left(\mathrm{W} \mathrm{m}^{-2}\right)$ & $(-)$ & $\left(\mathrm{W} \mathrm{m}^{-2}\right)$ & $\left(\mathrm{m} \mathrm{s}^{-1}\right)$ & $\left({ }^{\circ}\right)$ & $\left({ }^{\circ} \mathrm{C}\right)$ & $\left({ }^{\circ} \mathrm{C}\right)$ & $(\%)$ & $(\mathrm{hPa})$ & (m) \\
\hline Sensor & \multicolumn{3}{|c|}{ Kipp and Zonen CNRI } & \multicolumn{2}{|c|}{ Young 05103} & CNR1 & \multicolumn{2}{|c|}{ Vaisala HMP45 } & Setra278 & SR50 \\
\hline $26 / 12-11 / 12$ & 413 & 0.54 & 205 & 3.0 & 170 & -5.3 & -2.7 & 32.5 & 442 & 1.62 \\
\hline $12 / 12-20 / 12$ & 441 & 0.48 & 212 & 2.8 & 214 & -2.9 & -0.8 & 41.4 & 448 & 1.96 \\
\hline $21 / 12-03 / 01$ & 426 & 0.41 & 224 & 3.1 & 217 & -1.4 & 1.9 & 39.5 & 456 & 2.56 \\
\hline
\end{tabular}

two intervals at site B. The total surface lowering over the entire available period computed by volume change (hypsometric mean height change) was $1.68(1.77) \pm 0.11 \mathrm{~m}$ at site $A$ and $1.37(1.32) \pm 0.38 \mathrm{~m}$ at site B. Surface height changes recorded at site $\mathrm{A}$ over the same period as at site $\mathrm{B}$ were 1.35 $(1.31) \pm 0.21 \mathrm{~m}$, indicating that the values were repeatable at both sites. The volume loss was converted to mass loss using the mean snow density of $426 \mathrm{~kg} \mathrm{~m}^{-3}$ (with an assumed error of $\pm 5 \%$ ) measured in a $1.10 \mathrm{~m}$ snow pit excavated on 22 November 2013 beside the AWS. Mass loss at site A computed from mesh volume change (hypsometric height change) between 25 November and 3 January was $716 \pm 58$ $(754 \pm 59) \mathrm{kg} \mathrm{m}^{-2}$. Mass loss at site B from mesh volume changes (hypsometric height changes) between 11 December and 3 January was $582(562) \pm 166 \mathrm{~kg} \mathrm{~m}^{-2}$. Measurements at site A over the same period give mass loss of 573 (558) $\pm 95 \mathrm{~kg} \mathrm{~m}^{-2}$, so again, measurements at both sites are within error of each other.

The morphometry of the sampled penitentes changed visibly over the measured intervals (Figs. 3 and 4). The strong east-west lineation and preferred north and south surface aspect predicted from theory developed early and was maintained throughout the study period. Over time penitente troughs became fewer in number, but wider and deeper. This causes total surface area to increase; the true surface is between 1.7 and 4.0 times the horizontal equivalent area at site $A$ and between 2.1 and 3.7 times the horizontal surface area at site B (Fig. 4a and b). Snowfall during the first measurement interval decreases the surface area at site A over that interval. Surface relief, expressed by the vertical range of the mesh, also increases through time, except when snowfall partially filled the developing penitentes and reduces both the range of the surface and the general slope angle. The largest part of the surface is facing southwards, and the predominant angle generally steepens over time, though again this trend is reversed by snowfall (Fig. $4 \mathrm{c}$ and d). From the onset of measurements the surface aspect distribution is strongly dominated by north- and south-facing components and this becomes more pronounced in the latter measurements and the preferred orientation rotates slightly over the course of the season (Fig. 4e and f).

\subsection{Manual measurements of reference cross-profile}

The surface properties from manual measurements were computed on data sampled at $0.2 \mathrm{~m}$ over $5.0 \mathrm{~m}$. Maximum relief of the sampled penitente profile, defined as the range of the distance from the horizontal reference to the surface, increased over time from 0.76 , through 0.83 and 1.00 to $1.38 \mathrm{~m}$ on each measurement date. The standard deviation of the surface remained relatively unchanged with values of $0.24,0.26$, 0.28 and $0.32 \mathrm{~m}$ at each measurement date. Surface lowering rate calculated by differencing the mean surface height along the profile on each measurement data was 13, 57 and $61 \mathrm{~mm} \mathrm{~d}^{-1}$ over the three sampled intervals, giving a total mean surface lowering of $1.61 \pm 0.14 \mathrm{~m}$ between 23 November and 4 January. These manual measurements along the cross-profile compare well to the aerially averaged lowering rates from the scanned surfaces, despite the fact that the manual measurements are made in only two dimensions, do not visually represent the complexity of the penitente surfaces, and individual points are sometimes out of the range of error of the Kinect (Fig. 5). The computed mass loss over the same period is $688 \pm 70 \mathrm{~kg} \mathrm{~m}^{-2}$, which underestimates, but is within error of, the value for site A derived from volume changes.

To investigate the impact of sampling resolution, maximum elevation range, mean surface height compared to the horizontal reference and mean surface lowering were calculated from manual measurements at $0.1(n=52), 0.2(n=$ 26), $0.4(n=14)$ and $1.0 \mathrm{~m}(n=6)$ intervals on the last three measurement dates. The highest-resolution sample was taken as a reference against which to evaluate coarser sampling. Surface relief differed from that measured at $0.1 \mathrm{~m}$ by maxima of $0.13,0.29$ and $0.41 \mathrm{~m}$ for $0.2,0.4$ and $1.0 \mathrm{~m}$ sampling intervals respectively. Mean measured surface height was within $0.03 \mathrm{~m}$ of the highest-resolution measurements at 0.2 and $0.4 \mathrm{~m}$ intervals and within $0.12 \mathrm{~m}$ at $1.0 \mathrm{~m}$ resolution. Mean lowering rates at $0.1,0.2$ and $0.4 \mathrm{~m}$ sampling intervals were all within $3 \mathrm{~mm} \mathrm{~d}^{-1}$. This increased to a maximum of $12 \mathrm{~mm} \mathrm{~d}^{-1}$ when the sampling resolution was decreased to $1.0 \mathrm{~m}$. Decreasing the length of the sampled profile down to 
(a)

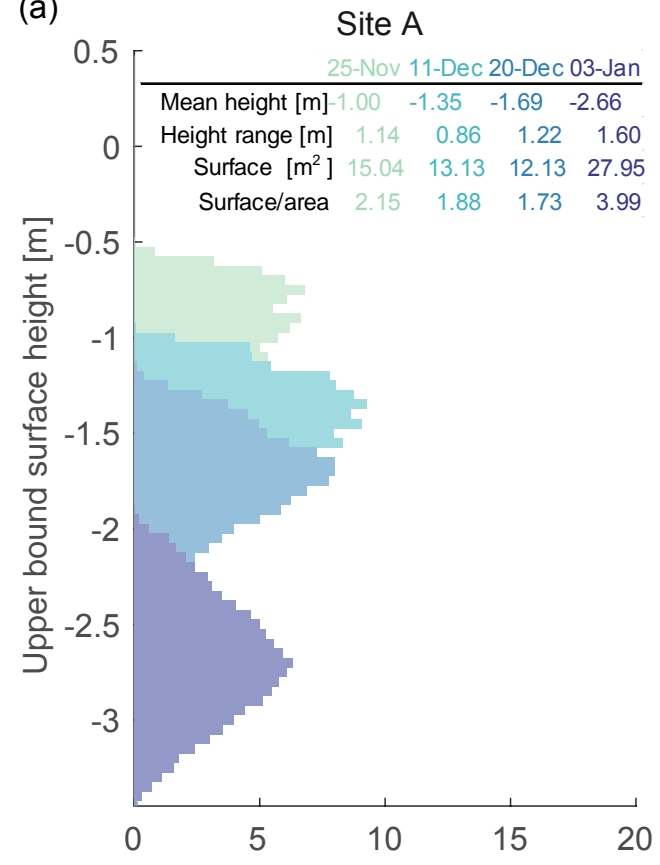

(c)

$\%$ of surface area

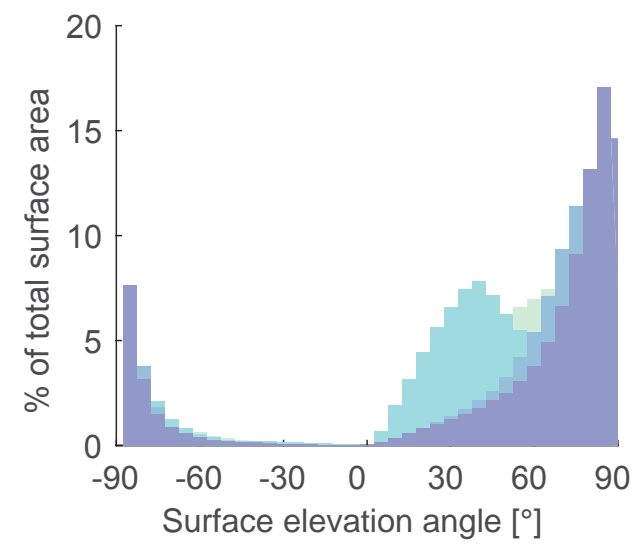

(e)

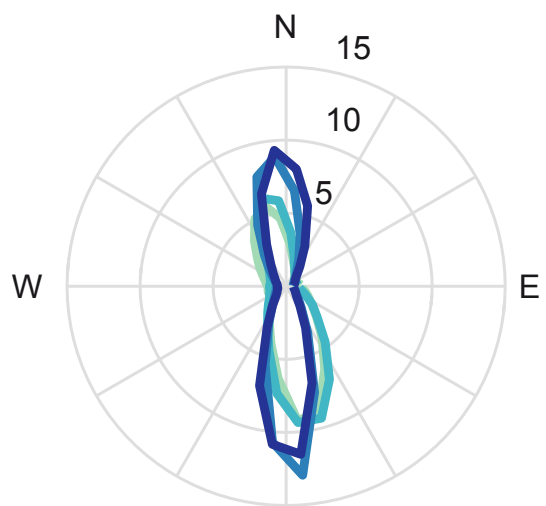

$S$ (b)

Site B

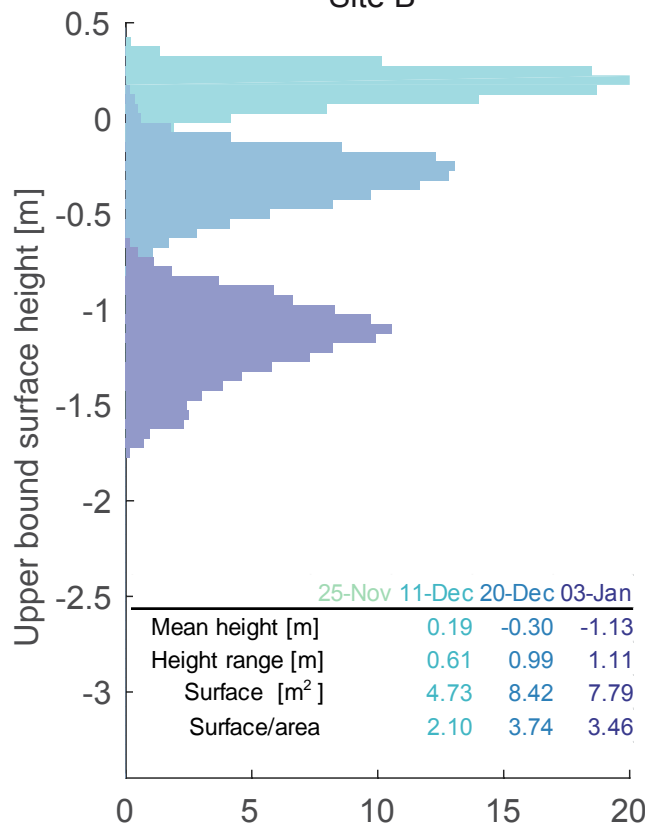

(d)

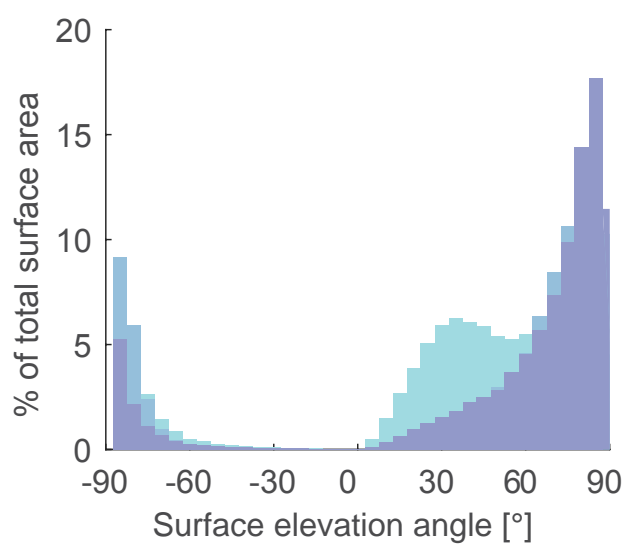

(f)

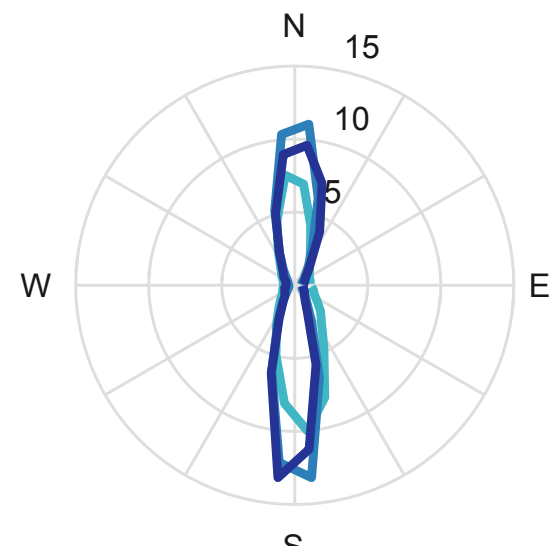

Figure 4. Summary of the DSM properties through time at sites A (left) and B (right). (a, b) Surface height distribution as a percentage of total surface area, in local coordinates $(\mathrm{m})$ relative to the position of the northern end of ablation frame. Inset tables show weighted mean mesh elevation, range, surface area and surface area as a function of the horizontal area of the sampled site. (c, d) Distribution of surface angles as a percentage of total surface area. $(\mathbf{e}, \mathbf{f})$ Aspect distribution as a percentage of total surface area. 


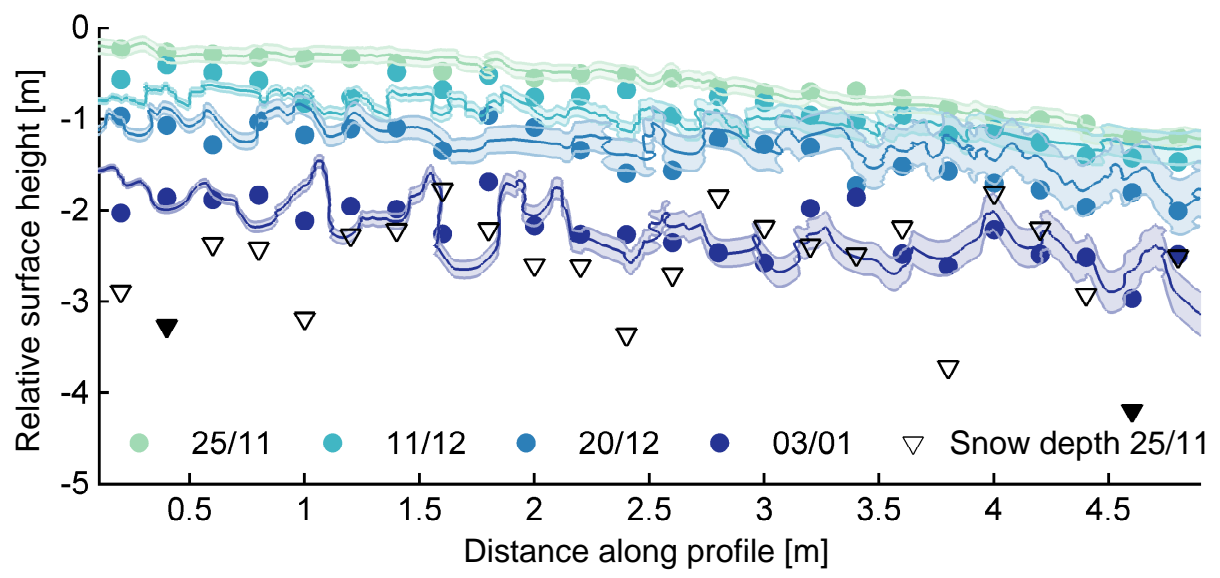

Figure 5. Comparison of surface height through time extracted from the Kinect scan and measured manually along the horizontal reference. Vertical error on the Kinect cross profiles is given by a linear interpolation of total positional error between the bounding stakes. Solid black triangles indicate locations where snow depth exceeded the length of the $3 \mathrm{~m}$ probe.

$2 \mathrm{~m}$ alters the mean lowering rate by less than $5 \mathrm{~mm} \mathrm{~d}^{-1}$ at sampling resolutions of $0.1,0.2$ and $0.4 \mathrm{~m}$.

Probing of the snow depth on 25 November indicated mean snow depth of $1.83 \mathrm{~m}$ (standard deviation $0.56 \mathrm{~m}$ ). The underlying ice surface does not appear to be influencing the structure of the overlying snow penitentes (Fig. 5). However, it is difficult to draw a firm conclusion based on these measurements, particularly as, while the surface of the penitentes was still snow on the 3 January, in several instances the surface had lowered below the level of the ice interface suggested by the initial probing.

\subsection{Surface roughness assessments}

Given that aerodynamic measurements to determine the most suitable representative height and zero displacement level for penitentes are thus far unavailable, the approach taken here was to do an exploratory study and compute geometric surface roughness values using various ways of expressing $h$ and $z_{\mathrm{d}}$. As a consequence the results are purely illustrative and while patterns can be drawn from them that have meaning for understanding the nature of the computation, the applicability of these values in turbulent exchange calculations remains to be established. The representative height, $h$, used in the calculations increases over time in all cases and is bounded by the maximum case, taking $h$ as range of the detrended surfaces, and the minimum case, taking $h$ as twice the standard deviation of the detrended surface (Fig. 6). For clarity, the two intermediate values are not included in Fig. 6. Differences in $h$ computed by the same method can reach as much as $0.2 \mathrm{~m}$ between the two sites, although the pattern of change over time is consistent.

The application of Lettau's (1969) formula is considered to be invalid if the ratio of the frontal area to the planar area of the obstacles exceeds $0.2-0.3$, with 0.25 often being chosen as a single value. This ratio is greater than 0.2 for all

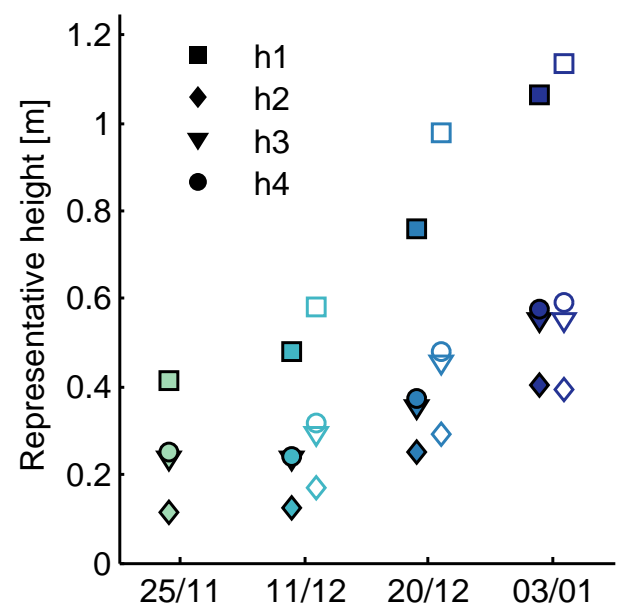

Figure 6. Representative surface heights computed on detrended surface meshes for site A (solid) and site B (open) over time, where $h 1-h 4$ refer to the representative surface heights computed as range $(h 1)$, twice the standard deviation ( $h 2$ ), area weighted mean height above the minimum $(h 3)$ and area weighted median above the minimum mesh height $(h 4)$.

of the penitente surfaces and after 20 December is always greater than 0.3. Exceeding this threshold implies that the obstacles are so closely packed that "skimming" airflow will occur. Ignoring this issue, calculated $z_{0}$ values increase with time and show a strong dependence on the impinging wind direction, with values peaking for wind directions perpendicular to the alignment of the penitentes (Fig. 7). Calculated $z_{0}$ ranges from 0.01 to $0.90 \mathrm{~m}$, depending on the way in which the representative height is expressed, the date and the wind direction (Fig. 8). However, given the close spacing of the penitentes it is likely more valid to explore what the calculated $z_{0}$ would be when a zero displacement height offset is applied. Again, in the absence of validation data from inde- 
pendent measurements, calculated values can be only indicative of the pattern of roughness computed by these methods. Introducing the zero displacement height reduces the maximum calculated roughness by about half and also reduces the variability between different representative heights (Fig. 8), as a smaller $h$ value translates into a smaller $z_{\mathrm{d}}$ so that the calculation is performed on a larger portion of the mesh.

Surface roughness assessments on the basis of calculations following Munro's modification for single profile measurements were applied to cross profiles longer than $1.5 \mathrm{~m}$, yielding 20 (6) profiles orientated $\mathrm{N}-\mathrm{S}$ and 33 (7) E-W at site A (B). Surface amplitude increases over time, and the amplitude of the $\mathrm{N}-\mathrm{S}$ running cross profiles is generally larger than the E-W running cross profiles, as illustrated in the example of site B (Fig. 9). Table 3 shows the calculated roughness values at each survey date, revealing that while profile-computed roughness length increases monotonically over time at site B, it reduces over the first period at site A, associated with snowfall during this period. Both the range and relative increase in roughness over time is larger for the $\mathrm{N}-\mathrm{S}$ running profiles. The computed roughness at both sites is 4.3 to 6.8 times larger for airflow impinging on the penitente field in an E-W direction than for airflow in the $\mathrm{N}-\mathrm{S}$ direction. This is contrary to the results computed on the full 3-D mesh surface but is understandable because this formulation relies on the amplitude of the surface, which is generally larger in the $\mathrm{N}-\mathrm{S}$-orientated cross profiles than the $\mathrm{E}-\mathrm{W}$ running cross profiles.

\section{Discussion}

\subsection{Penitente morphology}

Although the natural penitentes sampled here are more convoluted than the parallel rows of penitentes used in model representations (Corripio and Purves, 2005; Lhermitte et al., 2014), the morphometric properties of the meshes broadly meet the properties of simplified surfaces. The penitente surface represents a much larger total surface area than the equivalent non-penitente surface and the control of solar radiation on penitente morphology means that the vast majority of the surface consistently dips steeply to the north and south at all stages of development. This means that the angle of incidence of direct solar radiation is reduced, decreasing both the intensity of the solar beam and the proportion of it that is absorbed. Although these effects are counteracted by multiple reflections of solar radiation within the penitente (Corripio and Purves, 2005; Lhermitte et al., 2014; Claudin et al., 2015) modelled mean net shortwave at sampled points in an example penitente field at the summer solstice at $33^{\circ} \mathrm{S}$ is about half of that of a level surface (Corripio and Purves, 2005). However, given the larger surface area of the penitente field compared to a flat surface, the total absorbed shortwave is a third higher in the modelled penitentes, broadly in line with the observed effect of penitentes on spatially averaged albedo (Warren et al., 1998; Corripio and Purves, 2005; MacDonell et al., 2013; Cathles et al., 2014; Lhermitte et al., 2014). For idealized penitentes at $33^{\circ} \mathrm{S}$ during summer solstice, modelled increase in net shortwave radiation over penitentes is not compensated by modelled changes in net longwave radiation, meaning that the excess energy receipts must be compensated by either turbulent energy fluxes or consumption of energy by melting (Corripio and Purves, 2005).

Unless a snowfall event occurs to partially fill the troughs, surface relief, slope angle, penitente spacing and total surface area all increase over time as the penitentes develop and deepen. Thus the impact of penitentes on surface properties will also change along with the morphological changes. At Tapado Glacier, penitentes are initially overhanging to the north, and the south-facing sides are convex compared to the north-facing overhanging faces. Over the season the penitentes become more upright as the noon solar angle gets higher. Idealized modelling based on measurements at Tapado Glacier shows that concave and convex slopes, as well as penitente size, impact the apparent albedo as measured by ground and satellite sensors (Lhermitte et al., 2014), and there may be some value in assessing the impact of these morphometry changes on albedo over time. In the context of the numerical theory of Claudin et al. (2015), penitente spacing controls the atmospheric level at which water vapour content is representative of the bulk surface properties. Simultaneous field or laboratory measurements of penitente spacing evolution and vapour fluxes above the surface would be required to solidly confirm this, but the spacing from the field measurements provided here can be used as an indication of the level at which measurements would need to be made in order to capture the bulk surface fluxes rather than fluctuations governed by the small-scale surface terrain.

\subsection{Methods of measuring change of rough glacier surface elements}

The test site for scanning penitentes with a TLS was chosen as scanning positions could be established on the surrounding higher ground overlooking the penitente field, thereby offering the best viewing angles possible. Nevertheless, the terrestrial laser scanning could only capture the upper portions of the penitentes. As ablation is at its maximum in the troughs, TLS data are therefore not able to determine the true volume change of penitentes. The coverage would be increased if a higher viewing angle could be achieved, but the steep, dense nature of penitente fields makes it difficult to imagine where sufficient suitable locations can be found surrounding glaciers or snowfields with penitentes. In contrast, the mobile Kinect sensor can be moved across the complex relief of the penitente field to make a complete surface model. Although it is in principle possible to capture a large area with the ReconstructMe software used here, and it offers the ad- 


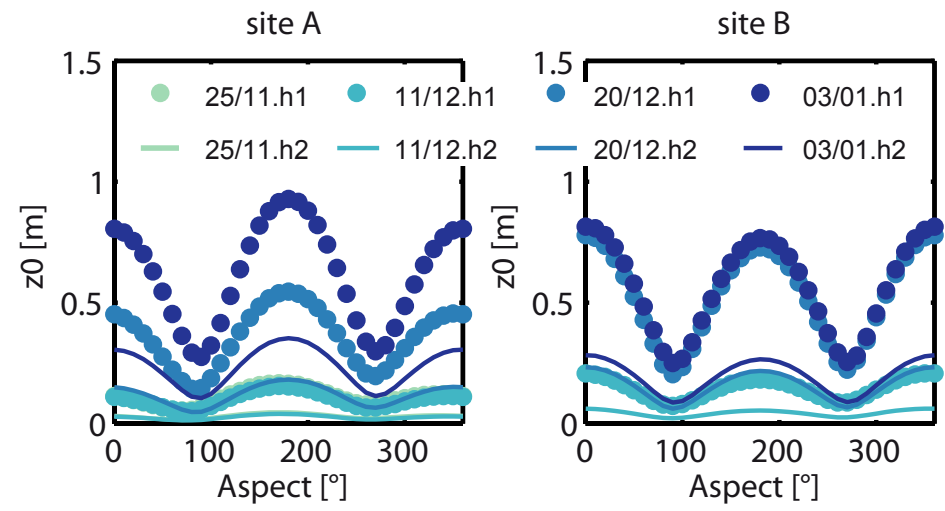

Figure 7. Three-dimensional $z_{0}$ computed for $10^{\circ}$ aspect intervals for all detrended DSMs highlighting peak roughness that occurs in $\mathrm{N}-\mathrm{S}$ airflow. Maximum values take $h$ to be the detrended mesh elevation range, and minimum values take $h$ to be twice the standard deviation of the detrended mesh.

Table 3. Surface roughness $\left(z_{0}\right)$ computed according to Munro (1989) on detrended profiles longer than $1.5 \mathrm{~m}$, extracted at $0.10 \mathrm{~m}$ intervals from the Kinect surface meshes at sites $\mathrm{A}$ and $\mathrm{B}$ for $\mathrm{E}-\mathrm{W}$ impinging wind and $\mathrm{N}-\mathrm{S}$ impinging wind. The number of profiles used for each wind direction is given in parentheses. The likely displacement of the zero velocity plane (d_top \pm standard deviation) was computed as the mean of $2 / 3 h$ for all profiles and expressed as a distance from the top of the penitentes. The range of the detrended 3-D mesh (3-D range) provides a reference for the penetration depth of turbulence.

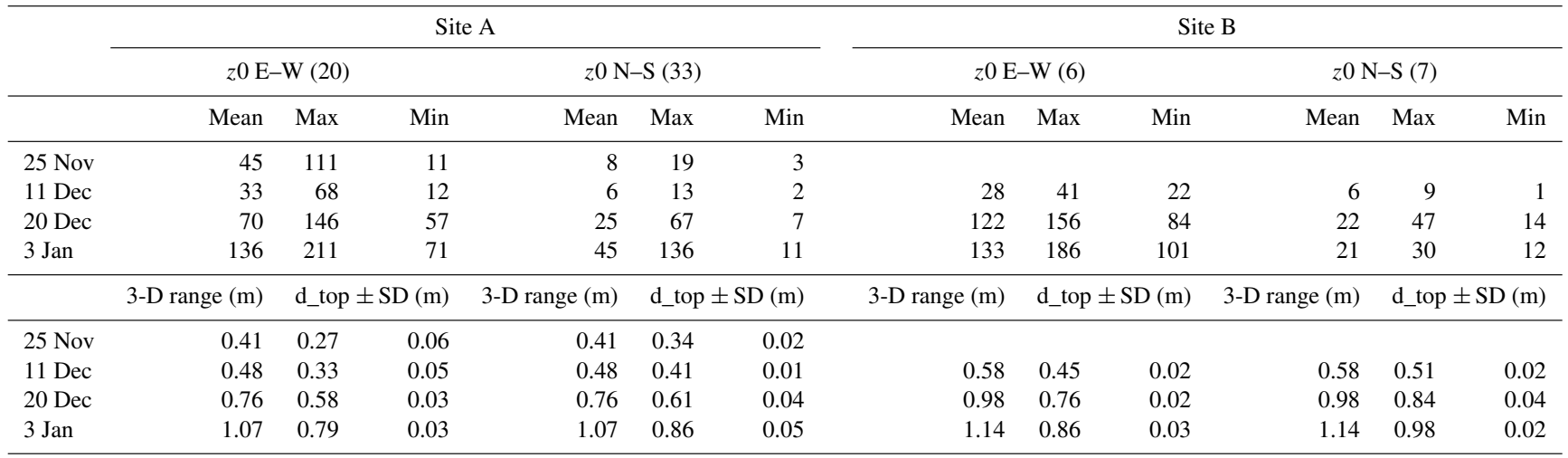

vantage of providing real-time feedback on the mesh coverage, it proved difficult to capture the study sites in a single scan given (i) the reduced signal range of the sensor over snow and ice (Mankoff and Russo, 2013) and (ii) the difficulty of moving around the penitente field. As a result, partial scans were obtained, with the disadvantage that subsequently combining these introduces a substantial degree of additional error associated with alignment if the component scans were not of high quality at the margins or did not overlap adjacent scan areas sufficiently. A combination of these two techniques might allow the extrapolation of small-scale geometry changes and volume loss determined from a Kinect surface scan to be extrapolated usefully to the glacier or snowfield scale using measurements made with a TLS.

Despite not visually capturing the complex morphology of the penitentes, manual measurements of surface height change in a penitente field along a profile crosscutting the penitentes are robust for determining mean surface lower- ing rates, and they show good agreement with the volume changes computed from differencing the digital surface models scanned in detail using a Kinect. Thus, the detailed surface geometry need not be known in order to reasonably calculate the total volume loss over time within penitente fields. Comparison of the manual sampling at different intervals suggests that five samples per metre are adequate to characterize surface change of penitentes but that data will be unreliable if the cross-profile is too short. Over the 39 days of the study, mass loss calculated from 26 points spaced at $0.2 \mathrm{~m}$ intervals along a $5 \mathrm{~m}$ profile crosscutting the penitentes differed from that calculated from volume change computed on surface meshes consisting of over 1.3 million points and covering an area of $7 \mathrm{~m}^{2}$ by only $28 \mathrm{~kg} \mathrm{~m}^{-2}$. Although this difference was within the error of the two measurement types, the seasonal difference, assuming that this difference applies to a whole ablation season of 120 days would be $86 \mathrm{~kg} \mathrm{~m}^{-2}$, and applied to the whole glacier $\left(3.6 \mathrm{~km}^{2}\right)$ would amount to 

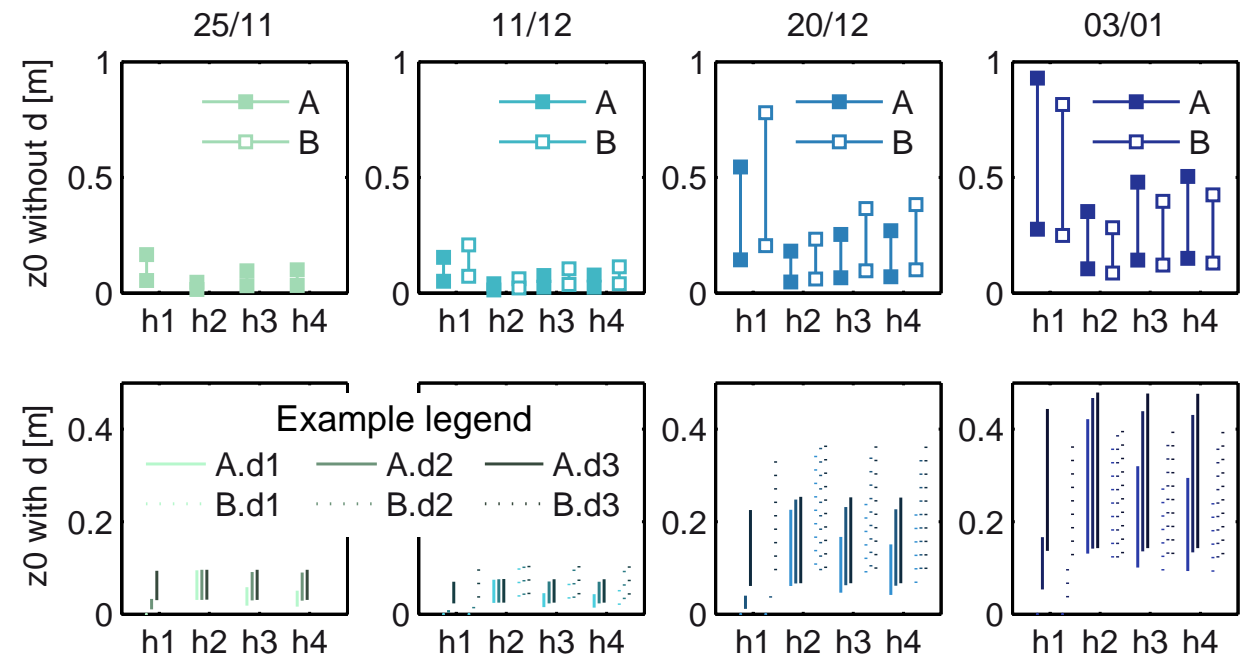

Figure 8. Comparison of three-dimensional surface roughness through time, indicating the range of $z_{0}$ computed for all incident wind angles (at $10^{\circ}$ intervals). Upper panels show the roughness with no zero level displacement and lower panels show values with a zero displacement offset $d 1=h ; d 2=2 / 3 h$ and $d 3=1 / 3 h$. As before, $h 1-h 4$ refer to representative surface heights computed as range, twice the standard deviation, area weighted mean height above the minimum and area weighted median above the minimum mesh height respectively.

an underestimate of mass loss over an ablation season of 0.3 gigatonnes. As a side note, the probing of snow depth carried out as part of this study highlights the difficulty in identifying the underlying ice surface, or summer ablation surface, within a penitente field, suggesting that a single location must be sampled very densely to obtain a characteristic snow depth by this method.

\subsection{Surface roughness}

The changing morphometry of the penitentes alters the geometrical surface roughness as they develop over the ablation season. Values calculated using a single, simple, geometric relationship (Lettau, 1969) were investigated because a profile-based version of this formulation has previously been tested against aerodynamic measurements over glacier surfaces (Munro, 1989, 1990; Brock et al., 2006). Certainly other relationships could be explored in the context of linearized glacier features, but given the wide spread of values produced in previous comparisons such an analysis might be of limited value in the absence of simultaneous aerodynamical investigations (Grimmond and Oke, 1999). Furthermore, the results of Grimmond and Oke (1999) indicate that for the cities sampled, the Lettau method gives $z_{0}$ values that are in the middle of the range of all the methods. The analysis of geometric computations of roughness properties in Grimmond and Oke (1999) highlights the importance of correctly determining $z_{\mathrm{d}}$, and limited sensitivity analyses show the computed $z_{\mathrm{d}}$ and $z_{0}$ to be strongly dependent on the dimensions of the obstacles. Lettau's (1969) formula, which does not account for $z_{\mathrm{d}}$, overestimates roughness for densely packed obstacles, but this does not compensate sufficiently to reproduce values of $z_{\mathrm{d}}+z_{0}$ for densely packed obstacles from formulations that include $z_{\mathrm{d}}$ in the computation of $z_{0}$. Thus, Lettau's formula is expected to estimate the zero velocity point of a logarithmic wind profile to be lower than formulations that include $z_{\mathrm{d}}$ in the computation of $z_{0}$.

The ratio of frontal to planar area of the penitentes implies that skimming flow prevails, such that turbulent airflow in the overlying atmosphere does not penetrate penitente troughs. This is in agreement with the theory of formation and growth of penitentes, in which the development and preservation of a humid microclimate within the penitente troughs is required to facilitate differential ablation between the trough and tip of the penitente. Although the data here show that penitentes become less densely packed over time, skimming flow regime persists over the study period, and available data are insufficient to determine whether this holds true to the end of the ablation season.

Application of geometrical roughness equations is made more problematic in penitente fields as it is not clear how an appropriate representative obstacle height should be expressed or how to define the zero displacement level during skimming flow. Roughness calculated using a range of possible representations of these properties points towards roughness values on the order of $0.01-0.10 \mathrm{~m}$ during the early part of the ablation season and $0.10-0.50 \mathrm{~m}$ after the end of December. These values are greater than the roughest values previously published for glacier ice, which are $<0.10 \mathrm{~m}$ (Smeets et al., 1999; Obleitner, 2000). The topographic analysis clearly shows that in the absence of intervening snowfall events, this roughness increase is related to the deepening of the penitentes over time and an increase of the surface amplitude. The pattern of the computed roughness properties is consistent between the two neighbouring sites, but individual 

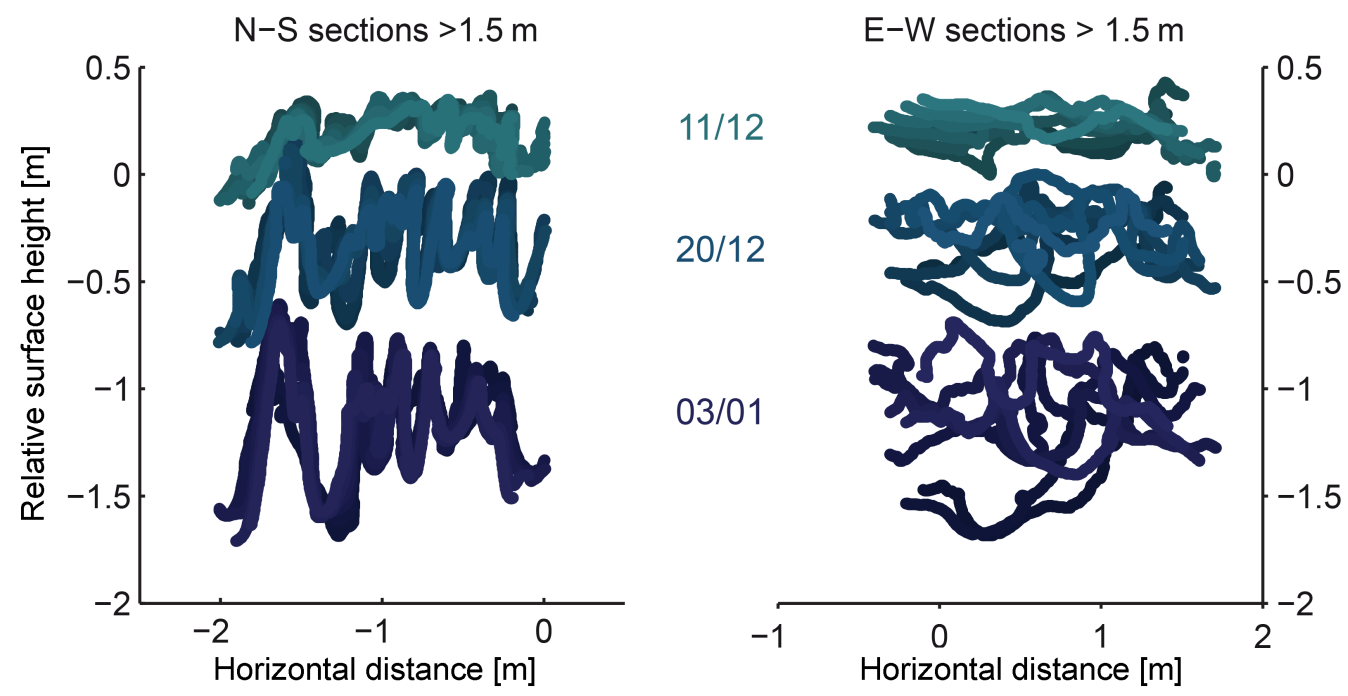

Figure 9. Examples of (a) $\mathrm{N}-\mathrm{S}$ and (b) E-W-orientated cross sections longer than $1.5 \mathrm{~m}$, sampled at $0.1 \mathrm{~m}$ intervals from which effective surface roughness properties were computed using the methods of Munro $(1989,1999)$. The local coordinates are relative to the NE corner marker of site A (Fig. 1).

values can differ, suggesting that relief varies substantially over short distances and sampling a large area is necessary to capture mean properties.

The dependence of topographic roughness determinations on wind direction has been illustrated in previous studies (e.g. Jackson and Carol, 1978; Smith et al., 2016), and this is exceptionally so for the strongly aligned penitentes. Roughness calculated from 3-D surface meshes is higher for wind impinging in a north-south direction, as the large faces of the penitentes form the frontal area in this case. In contrast, roughness calculated for individual profiles extracted from the mesh to mimic manual transect measurements in the field, is between 3 and 6 times larger for air flow impinging in an east-west direction than in a north-south direction. Neither approach has been evaluated against independent surface roughness derived from atmospheric profile measurements over penitentes. Consequently, although surface roughness calculations on the basis of profile geometry have been evaluated against aerodynamic roughness over rough ice surfaces, the available data are insufficient to distinguish if maximum aerodynamic roughness is associated with wind flowing across or along the penitente lineation. Thus it is not clear which method captures the appropriate relationship between wind direction and surface roughness for calculating turbulent fluxes over penitentes. It principle it sounds reasonable to expect airflow across the penitente lineation to maximize turbulence as the penitentes present a large surface area to the wind; however, if skimming flow is established, with the result that only the tips of the penitentes are determining the structure of the turbulence, then roughness in this direction would be strongly reduced and perhaps even be less than for air flow along the penitente lineation, for which the smaller frontal area reduces the likeli- hood of skimming flow. Further investigation of this in order to quantify the impact of penitentes on turbulent fluxes for various airflow patterns requires measurement of turbulent fluxes using eddy covariance or atmospheric profile methods, which would demonstrate the nature of the directional roughness and establish the impact of penitentes on turbulent energy fluxes for different wind directions. Such measurements would be best implemented in a manner which can sample all wind directions equally, and eddy covariance systems for which analysis is limited to a sector of airflow centred around the prevailing airflow source might not be able to capture the nature of the directional dependence correctly.

Prevailing wind direction differs only slightly in each period with an increasing north-westerly component in the second two periods compared to the first. This may be related to the occurrence of snow during the first period, which is expected to alter thermally driven valley wind systems. Over the entire study period wind direction is predominantly from the south-easterly and north-westerly sectors and swings through both extreme wind angles used in the roughness calculations here (Fig. 10). This indicates that the effective roughness at this site can be expected to differ significantly over time depending on the wind direction.

In this study we did not explicitly compute the blending height as available formulae are dependent upon $z_{0}$ and $z_{\mathrm{d}}$. Estimates of the blending height independently from $z_{0}$ and $z_{\mathrm{d}}$ have been suggested to be $2.5-4.5$ times $h$, twice the mean element spacing or a combination of the height and spacing (see examples within Grimmond and Oke, 1999). Given that only atmospheric measurements above the blending height give representations of integrated surface fluxes and conditions, the first approach would imply that aerodynamical or flux measurements over penitentes would have to be car- 


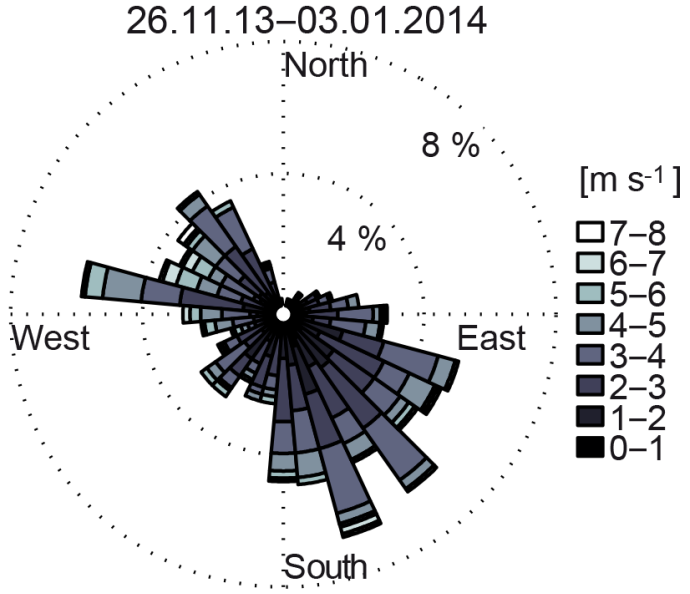

Figure 10. Wind rose for the entire study period (26 November 2013-3 January 2014).

ried out at considerable height above the surface to capture mean surface properties rather than the effects of individual roughness elements. The mathematical model of Claudin et al. (2015) gives a characteristic length scale for the level at which the vapour flux is constant in horizontal space that is related to the spacing of the penitentes. Interpreting this level as the blending height implies that the blending height might be determined on the basis of spacing of penitentes alone, and that this in turn might contain useful data for understanding the structure and efficiency of turbulence above penitentes. Exploring these ideas requires information from detailed meteorological measurements as well as the geometrical information offered in this paper.

\section{Conclusions}

Surface scanning technology and software is an area of rapid development, and a number of potentially superior alternative set-ups and data-capture sensors and software are now available. This study demonstrates that the Microsoft Kinect sensor can work successfully at close range over rough snow and ice surfaces under low light conditions and can generate useful data for assessing the geometry of complex terrain and surface roughness properties. The data collected offer the first detailed study of how the geometry of penitentes evolve through time, highlighting the rate of change of surface properties over an ablation season that can serve as a guideline for parameterizing surface properties required for energy and mass balance modelling of penitente surfaces.

The results confirm that even relatively crude manual measurements of penitente surface lowering are adequate for quantifying the seasonal mass loss, which is good news for the validity of measurements of surface change on glaciers with penitentes. However, further measurements and/or modelling studies are required to determine whether the mass loss from the expanded and convoluted surface of penitentes is enhanced or inhibited compared to mass loss in the absence of penitentes.

Aerodynamical roughness properties and related metrics over very rough surfaces remain poorly quantified and both geometric and meteorological determinations of these values show a wide spread; consequently it remains unclear what the best methods to use are or what values modellers would be best to use (Grimmond and Oke, 1999). In this context further study of penitentes offers a useful opportunity because (a) their morphometric evolution over time allows various geometries to be evaluated by monitoring a single site and (b) they offer a bridge between wind tunnel and urban field experimentation of turbulence and roughness over extreme terrain. Although validity of surface roughness calculations based on surface geometry remains to be established for penitentes, this study highlights that (i) skimming flow is expected to persist over penitentes field but is more likely under wind directions perpendicular to the penitente alignment; (ii) $z_{\mathrm{d}}$ is certainly greater than 0 , and while the depth of penetration of surface layer turbulence into a penitente field is not clearly established it is likely to evolve with the developing penitentes, and values of $z_{\mathrm{d}} \sim 2 / 3 h$ give results that are theoretically reasonable in the framework outlined by Grimmond and Oke (1999); (iii) the two methods of geometric computation of surface roughness applied here give conflicting results as to whether the effective surface roughness of penitentes is greater for airflow along or across the penitente lineation; and (iv) more complete understanding of the impact of penitentes on the turbulent structure, its evolution in time and its directional dependency would require atmospheric measurements with no directional bias concurrent with measurements of penitentes morphology.

Potential future applications and analyses of the surfaces generated in this study include (i) using surface properties and roughness values as a guide for input into surface energy balance models, (ii) assessing the performance of models against the measured volume loss over time and (iii) evaluating how well simplified representations of penitente surfaces used in small-scale radiation models and turbulence models capture the real-world complexity. Such studies would help establish the nature of the likely microclimatic distribution of the surface energy balance within a real penitente field and as a result the impact of penitentes on runoff and exchange of water vapour with the atmosphere.

\section{Data availability}

Surface meshes used in this study are provided in the Supplement (naming convention is site _ddmm.ply). Interactive 3-D views of surfaces from site $\mathrm{B}$ can be seen at https://sketchfab.com/LindseyNicholson/folders/ penitentes-on-glaciar-tapado-chile (Nicholson, 2016). Processing scripts are available on request. 


\section{The Supplement related to this article is available online at doi:10.5194/tc-10-1897-2016-supplement.}

Author contributions. L. I. Nicholson designed the study. Fieldwork was carried out by L. I. Nicholson and B. Partan with M. Pętlicki providing the TLS data. TLS and AWS equipment was provided by $S$. MacDonell through collaboration with CEAZA. The data were analysed by L. I. Nicholson and M. Pȩtlicki. Preparation of the manuscript and figures was led by L. I. Nicholson with contributions from all co-authors.

Acknowledgements. Fieldwork for this study was funded by a National Geographic Waitt Grant awarded to L. I. Nicholson and S. MacDonell. L. I. Nicholson was supported by an Austrian Science Fund Elise Richter Grant (V309). MP was supported within statutory activities no. 3841/E-41/S/2016 of the Ministry of Science and Higher Education of Poland. International cooperation was supported by the Centre for Polar Studies from the funds of the Polish Leading National Research Centre (KNOW) in Earth Sciences (2014-18). Thanks are also due to Mathias Rotach for reading the paper prior to submission.

Edited by: T. Bolch

Reviewed by: R. Naruse and one anonymous referee

\section{References}

Amstutz, G. C.: On the formation of snow penitentes, J. Glaciol., 3, 304-311, 1958.

Andreas, E. L.: A relationship between the aerodynamic and physical roughness of winter sea ice, Q. J. Roy. Meteor. Soc., 137, 1581-1588, doi:10.1002/qj.842, 2011.

Bergeron, V., Berger, C., and Betterton, M. D.: Controlled irradiative formation of penitentes, Phys. Rev. Lett., 96, 098502, doi:10.1103/PhysRevLett.96.098502, 2006.

Blumberg, D. and Greeley, R.: Field studies of aerodynamic roughness length, J. Arid Environ., 25, 39-48, doi:10.1006/jare.1993.1041, 1993.

Brock, B. W., Willis, I. C., and Sharp, M. J.: Measurement and parameterization of aerodynamic roughness length variations at Haut Glacier d'Arolla, Switzerland, J. Glaciol., 52, 281-297, doi:10.3189/172756506781828746, 2006.

Brutsaert, W.: A theory for local evaporation (or heat transfer) from rough and smooth surfaces at ground level, Water Resour. Res., 11, 543-550, 1975.

Cathles, L. M., Abbot, D. S., and MacAyeal, D. R.: Intrasurface radiative transfer limits the geographic extent of snow penitents on horizontal snowfields. J. Glaciol., 60, 147-154, doi:10.3189/2014JoG13J124, 2014.

Claudin, P., Jarry, H., Vignoles, G., Plapp, M., and Andreotti, B.: Physical processes causing the formation of penitentes, Phys. Rev. E, 92, 033015, doi:10.1103/PhysRevE.92.033015, 2015.
Corripio, J. G. and Purves, R. S.: Surface energy balance of high altitude glaciers in the Central Andes: the effect of snow penitentes, in: Climate and Hydrology in Mountain Areas, edited by: De Jong, C., Collins, D. N., and Ranzi, R., Wiley and Sons, Chichester, 15-27.

Drewry, D. J.: Snow penitents, Weather, 25, p. 556, 1970.

Fassnacht, S. R., Stednick, J. D., Deems, J. S., and Corrao, M. V.: Metrics for assessing snow surface roughness from Digital imagery, Water Resour. Res., 45, W00D31 doi:10.1029/2008WR006986, 2009a.

Fassnacht, S. R., Williams, M. W., and Corrao, M. V.: Changes in the surface roughness of snow from millimetre to metre scales, Ecol. Complex., 6, 221-229, doi:10.1016/j.ecocom.2009.05.003, 2009b.

Fassnacht, S. R., Oprea, I., Borlekse, G., and Kamin, D.: Comparing Snowpack Surface Roughness Metrics with a Geometric-based Roughness Length, in: Proceedings of the AGU Hydrology Days 2014 Conference, 44-52, 2014.

Grimmond, C. S. B. and Oke, T. R.: Aerodynamic Properties of Urban Areas Derived from Analysis of Surface Form, J. Appl. Meteorol., 38, 1262-1292, 1999.

Hastenrath, S. and Koci, B.: Micro-morphology of the snow surface at the Quelccaya ice cap, Peru, J. Glaciol., 27, 423-428, 1981.

Jackson, B. S. and Carroll, J. J.: Aerodynamic roughness as a function of wind direction over asymmetric surface elements, Bound.-Lay. Meteorol., 14, 323-330, doi:10.1007/BF00121042, 1978.

Kaser, G., Großhauser, M., and Marzeion, B.: Contribution potential of glaciers to water availability in different climate regimes, P. Natl. Acad. Sci. USA, 107, 20223-20227, doi:10.1073/pnas.1008162107, 2010.

Kondo, J. and Yamazawa, H.: Aerodynamic roughness over an inhomogeneous ground surface, Bound.-Lay. Meteorol., 35, 331348, 1986.

Lettau, H.: Note on Aerodynamic Roughness-Parameter Estimation on the Basis of Roughness-Element Description, J. App.. Meteor., 8, 828-832, 1969.

Lhermitte, S., Abermann, J., and Kinnard, C.: Albedo over rough snow and ice surfaces, The Cryosphere, 8, 1069-1086, doi:10.5194/tc-8-1069-2014, 2014.

Lliboutry, L.: The origin of penitents, J. Glaciol., 2, 331-338, 1954.

Lliboutry, L.: Glaciers of Chile and Argentina, in: Satellite image atlas of glaciers of the world: South America, edited by: Williams, R. S. and Ferrigno, J. G. USGS Professional Paper 1386-I, 1998.

Macdonald, R. W., Griffiths, R. F. F., and Hall, D. J. J.: An improved method for the estimation of surface roughness of obstacle arrays, Atmos. Environ., 32, 1857-1864, doi:10.1016/S13522310(97)00403-2, 1998.

MacDonell, S., Kinnard, C., Mölg, T., Nicholson, L., and Abermann, J.: Meteorological drivers of ablation processes on a cold glacier in the semi-arid Andes of Chile, The Cryosphere, 7, 1513-1526, doi:10.5194/tc-7-1513-2013, 2013.

Mankoff, K. D. and Russo, T. A.: The Kinect: a low-cost, highresolution, short-range 3D camera, Earth Surf. Proc. Landf., 38, 926-936, doi:10.1002/esp.3332, 2013.

Manninen, T., Anttila, K., Karjalainen, T., and Lahtinen, P.: Automatic snow surface roughness estimation using digital photos, J. Glaciol., 58, 993-1007, doi:10.3189/2012JoG11J144, 2012. 
Munro, D. S.: Surface roughness and bulk heat transfer on a glacier: comparison to eddy correlation, J. Glaciol., 35, 343-348, 1989.

Munro, D. S.: Comparison of Melt Energy Computations and Ablatometer Measurements on Melting Ice and Snow, Arct. Antarct. Alp. Res., 22, 153-162, doi:10.2307/1551300, 1990.

Naruse, R. and Leiva, J. C.: Preliminary study on the shape of snow penitentes at Piloto Glacier, the central Andes, Bull. Glaciol. Res., 15, 99-104, 1997.

Nicholson, L.: Penitentes on Glaciar Tapado, Chile, available at: https://sketchfab.com/LindseyNicholson/collections/ penitentes-on-glaciar-tapado-chile, last access: 30 August 2016.

Obleitner, F.: The energy budget of snow and ice at Breidamerkurjökull, Vatnajökull, Iceland, Bound.-Lay. Meteorol., 97, 385$410,2000$.

Sinclair, K. and MacDonell, S.: Seasonal evolution of penitente geochemistry at Tapado Glacier, northern Chile, Hydrol. Process., 30, 176-186, doi:10.1002/hyp.10531, 2015.

Smeets, C. J. P. P., Duynkerke, P., and Vugts, H.: Observed wind profiles and turbulence fluxes over an ice surface with changing surface roughness, Bound.-Lay. Meteorol., 92, 99-121, 1999.
Smith, M. W., Quincey, D. J., Dixon, T., Bingham, R. G., Carrivick, J. L., Irvine-Flynn, T. D. L., and Rippin, D. M.: Aerodynamic roughness of glacial ice surfaces derived from highresolution topographic data, J. Geophys. Res.-Earth, 121, 748766 doi:10.1002/2015JF003759, 2016.

Thomsen, L. M., Baartman, J. E. M., Barneveld, R. J., Starkloff, T., and Stolte, J.: Soil surface roughness: comparing old and new measuring methods and application in a soil erosion model, SOIL, 1, 399-410, doi:10.5194/soil-1-399-2015, 2015.

Warren, S. G., Brandt, R. E., and O'Rawe Hinton, P.: Effect of surface roughness on bidirectional reflectance of Antarctic snow, J. Geophys. Res., 103, 25789-25807, 1998.

Winkler, M., Juen, I., Mölg, T., Wagnon, P., Gómez, J., and Kaser, G.: Measured and modelled sublimation on the tropical Glaciar Artesonraju, Perú, The Cryosphere, 3, 21-30, doi:10.5194/tc-321-2009, 2009. 